\title{
Limbic encephalitis: A scientometric analysis of global publications during 2004-13
}

\author{
Ritu Gupta, B. M. Gupta ${ }^{1 *}$, M. Mueen² \\ Sri Venkateshwar University, Meerut, 11173, Sector 15, Panchkula, Haryana, ${ }^{2}$ Phcog.Net and SciBiolMed, Bangalore, Karnataka, India
}

\begin{abstract}
The paper examines 901 global publications in limbic encephalitis as indexed in Scopus database during 2004-13, witnessing an annual average growth rate of $17.27 \%$ and an average citation impact per paper of 5.76. The limbic encephalitis publication output came from 48 countries, of which the top 10 (United States, Japan, U.K., Germany, France, Spain, Italy, etc.) accounted for $92.45 \%$ global publication share during 2004-13. Limbic encephalitis output came from 210 organizations, of which the top 10 contributed $19.98 \%$ share during 2003-12. The largest publication share (91.56\%) in limbic encephalitis came from medicine, followed by neurosciences (34.52\%), biochemistry, genetics and molecular biology $(6.77 \%)$, psychiatry $(4.66 \% 0$ and immunology and microbiology $(3.0 \%)$ Three countries, namely Spain, Austria and U.K. out of 10 have achieved higher share of relative index than the average relative citation index of 1.91 of top 10 countries during 2004-13.
\end{abstract}

Keywords: Global publications, limbic encephalitis, research trends, scientometrics methods

\section{INTRODUCTION}

The brain could be visualized in three segments: (i) The brain stem-the primitive part (sits above the spinal cord at the base of the rest of the brain), which supports the most basic functions of breathing, blood circulation and digestion, besides being involved in some of the basic aspects of behavior, mating, aggression and anger; (ii) limbic brain-wrapped around this basic brain and includes the hippocampus, thalamus, hypothalamus and amygdale, which are involved in memory and much of the behavior related to sex, hormones, food, the perception of pleasure and competition with others. It is also the seat of higher emotions including the protection of the young

*Address for correspondence:

E-mail: bmgupta1@gmail.com

\begin{tabular}{|l|l|}
\hline \multicolumn{2}{|c|}{ Access this article online } \\
\hline Quick Response Code: & Website: \\
\cline { 1 - 2 } & www.jscires.org \\
\cline { 2 - 3 } & DOI: \\
\hline
\end{tabular}

and feelings such as love, sadness and jealousy and (iii) the neocortical brain - It provides logic and thought and the seat of processes, such as speaking, planning and writing. ${ }^{[1-4]}$

Encephalitis is an inflammation of the brain. The inflammation is caused either by an infection invading the brain (infectious); or through the immune system attacking the brain in error (postinfectious or autoimmune encephalitis). The term "limbic encephalitis (LE) is used when the limbic areas of the brain are inflamed (swollen) or not functioning properly. The limbic system is a group of brain structures located beneath the cortex and more medial areas of the brain. The limbic system is noted to have several different important functions and represents the point where the subcortical brain structures meet the cortical brain structures. The limbic system influences the endocrine system that releases hormones and the autonomic nervous system, which is the part of the nervous system that controls muscles not considered to be under voluntary control. The limbic system also is connected with areas of the brain that are involved in reward and punishment. The limbic system functions by connecting all these complicated systems together and influences motivation, learning, memory and emotions. The symptoms of limbic 
encephalitis include memory loss, seizures, confusion, disturbances of sleep and psychological disturbances such as altered personality or behavior. ${ }^{[1-4]}$

Limbic encephalitis can be classified into two categories: (i) Infectious encephalitis - caused by direct invasion of the brain by an infectious agents, usually number of viruses, including the herpes simplex virus and (ii) Auto-immune encephalitis - caused by the persons own immune system reacting against itself. A major role of our immune system is to recognize and get rid of infection. But sometimes parts of the immune system - called "antibodies" - may instead react with proteins of our own body to cause autoimmune diseases. When this reaction is against proteins of the limbic areas of the brain, this is called "autoimmune limbic encephalitis. There are two forms of autoimmune limbic encephalitis, (i) paraneoplastic" limbic encephalitis (PLE) - Sometimes when the immune system starts to react with the limbic areas, this happens because the person has a growth, such as a cancer (tumor), which "activates" the immune system. In this case, the antibodies made by the patient in response to the growth, will attack the brain. Doctors call this PLE and (ii) nonparaneoplastic limbic encephalitis (NPLE) - It is caused, at least in part, by specific antibodies in the patient's blood that target the patient's brain tissue, particularly the hippocampus and other limbic areas. The antibody binds to a protein, present in all brain tissue: The potassium channel. This causes a reduction in the number of potassium channels, decreasing the control over electrical signals operating in the brain. Potassium channels are proteins that lie in the surrounding membrane of nerve cells in the brain and in the nerves that lead to the muscles of the skeleton, the gut and the heart. They are particularly common in the hippocampus and other limbic areas of the brain. ${ }^{[1-4]}$

\section{Literature Review}

No study is available till date on the quantitative analysis of literature in limbic encephalitis. However, only few studies are available on scientometric analysis of Japanese encephalitis. Garg et al. ${ }^{[5]}$ examined 2074 global publications during 1991-2010 in Japanese encephalitis, as indexed in SCI-expanded. The analysis focused on its research output growth, geographical distribution, research profile of different countries and their subject areas of focus, distribution of citation and citation impact of different countries and characteristics of leading productive institutions. In another publication, Garg and Dwivedi ${ }^{[6]}$ again examined 2074 publications in different aspects of highly collaborative discipline of Japanese encephalitis by different countries during 1991-2010. They examined the co-authorship index and the collaboration coefficient of different countries in different sub-fields, identified the pattern and magnitude of international collaboration in different sub-subfields, pattern of local, domestic and international collaboration and identification of leading prolific institutions in terms of strong international collaboration. Safahieh et al. ${ }^{[7]}$ studied 462 papers on Nipah virus, as covered in SCI-Expanded, a major cause of encephalitis during 1999-2010, with a focus on identifying the active authors, organizations and citations received. Szerwinski ${ }^{[8]}$ examined the entire spectrum of research in herpes simplex, as covered in using Web of Science and PubMed databases, during 1900-2007, USA (14,544) contributed the largest number of publications, followed by publications from some European countries and from Japan $(1,886)$, Canada $(1,229)$ and Australia $(545)$, etc. The trends in international collaboration of different countries were also examined. As expected, the focus of the most productive journals publishing research results were concentrated in virology, microbiology, immunology and infectology subject fields. The active authors were also studied regarding their number of publications and citations and also for their citation rate. The topical analysis shows a scientific focus on investigating herpes genitalis and HSV-encephalitis.

\section{OBJECTIVES}

The main objectives of this study are to analyze the research performance in limbic encephalitis during 2004-13, based on publications output covered in Scopus database. The study focuses in particular on the following objectives: (i) To study the global research output, its growth and citation impact; (ii) To study the contribution and citation impact of top 10 most productive countries; (iii) To examine the patterns of distribution of citations of the global research output; (iv) To study the international collaboration share in publication output of top 10 most productive countries and the extent of their inter-country collaborative linkages; (v) To study the distribution of global research output by broad subject areas; (vi) To study the publication productivity and citation impact of leading institutions; and (vii) To study the media of communication and the characteristics of the high cited publications

\section{METHODOLOGY}

The study retrieved global publication data and of top 10 most productive countries in limbic encephalitis from 
Scopus database (http:/ / www.scopus.com) for last 10 years (2004-2013). The keyword "limbic encephalitis" was used in "title, abstract and keyword" field tag and "2004-2013" in time field tag was used for searching the main publication data, which became the main search string. When this search string was restricted to individual country "tag," publications output data of respective top 10 countries were identified and downloaded. The citation impact data was collected using a 3 year citation window: Three years, 2 years, 1 year citation window was used for publications during 2004-11, 2012 and 2013. The main search strategy was restricted to "institutional" and "journal tag" for analyzing institutional and journals output. The study uses a number of absolute and relative indicators, including the raw count of papers, citations and international collaborative papers (ICPs), the average citation per paper, activity index and relative citation impact. Citation per paper is measured by the ratio of total number of citations and the total number of papers for a country or an institution. Relative citation index is defined as the ratio of country's share of world citations and country's share of world publications. The activity index is defined as a country's share of its total article output across subject field (s) relative to the global share of articles in the same subject field (s).

\section{ANALYSIS}

The global output in limbic encephalitis consisted of 901 publications during 2004-13, as indexed in Scopus database. It increased yearly from 43 in the year 2003-154 publications in the year 2013, indicating an annual average growth rate of $17.27 \%$. The cumulative publications in limbic encephalitis have increased from 311 during 2004-08-590 during 2009-13, registering a growth rate of $89.71 \%$. Of the total 901 publications, 597 were articles, 141 reviews, 68 letters, 32 conference papers, 29 notes, 11 editorials, 10 short surveys, etc. The total publications (901) in limbic encephalitis during 2004-13 have received 5191 citations on a 3 year citation window, leading to citation impact per paper of 5.76, decreasing from 7.16 during 2004-08-5.02 during 2009-13 [Table 1].

\section{Patterns of Distribution of Citations of Publications}

The number of citations received (11283) by global publications (901) in limbic encephalitis since their publication year (2004 onwards) was studied till May 2014. The average rate of citations per publication was reported to be 12.52 . Of the total publications, $31.41 \%$ did not get any citations (zero citation) and rest $68.59 \%$ were cited one or more times. Of the cited publications, $2.44 \%$ (received 100 or more citations) contributed $35.96 \%$ citations share, $3.33 \%$ (received $51-100$ citations) contributed $19.68 \%$ citations share, $3.77 \%$ (received $31-50$ citations) contributed $11.63 \%$ citations share, $13.87 \%$ (received 11-30 citations) contributed $19.73 \%$ citations share and the rest $45.17 \%$ (received $1-10$ citations) contributed $13.01 \%$ citations share [Table 2].

\section{Publication Share and Citation Impact of 10 Leading Countries}

The research output in limbic encephalitis came from 48 countries during 2004-13. Tables 3 and 4 lists the output and citations of 10 most productive countries that produced $92.45 \%$ of the total world output in limbic encephalitis. The global publication share of 10 most productive countries in limbic encephalitis varied from $3.91 \%$ to $21.42 \%$, with highest share $(21.42 \%)$ registered by USA, followed by Japan (18.76\%), U.K. (13.43\%), Germany (11.65\%), France $(9.43 \%)$, Spain $(6.22 \%)$, Italy (4.66\%), Austria and Australia (2.33\% each) and Netherlands (2.22\%) during 2004-13. The publication share has increased by $4.59 \%$

\begin{tabular}{lccc}
\multicolumn{4}{l}{$\begin{array}{l}\text { Table 1: Global output of publications and citations in } \\
\text { limbic encephalitis, } 2004-\mathbf{1 3}\end{array}$} \\
$\begin{array}{lccc}\text { Publication } \\
\text { period }\end{array}$ & $\begin{array}{c}\text { Number of } \\
\text { publications }\end{array}$ & $\begin{array}{c}\text { Number of } \\
\text { citations }\end{array}$ & $\begin{array}{c}\text { Average citation } \\
\text { per year }\end{array}$ \\
\hline 2004 & 43 & 256 & 5.95 \\
2005 & 49 & 257 & 5.24 \\
2006 & 50 & 317 & 6.34 \\
2007 & 74 & 771 & 10.42 \\
2008 & 95 & 626 & 6.59 \\
2009 & 81 & 489 & 6.04 \\
2010 & 116 & 1061 & 9.15 \\
2011 & 126 & 1049 & 8.33 \\
2012 & 113 & 226 & 2.00 \\
2013 & 154 & 139 & 0.90 \\
$2004-08$ & 311 & 2227 & 7.16 \\
$2009-13$ & 590 & 2964 & 5.02 \\
$2004-13$ & 901 & 5191 & 5.76 \\
\hline
\end{tabular}

\begin{tabular}{|c|c|c|c|c|}
\hline $\begin{array}{l}\text { Range of } \\
\text { citations }\end{array}$ & $\begin{array}{l}\text { Number of } \\
\text { publications }\end{array}$ & $\begin{array}{c}\text { Total } \\
\text { citations }\end{array}$ & $\begin{array}{l}\text { Percentage of } \\
\text { publications }\end{array}$ & $\begin{array}{l}\text { Percentage } \\
\text { of citations }\end{array}$ \\
\hline 0 & 283 & 0 & 31.41 & 0.00 \\
\hline $1-10$ & 407 & 1468 & 45.17 & 13.01 \\
\hline $11-30$ & 125 & 2226 & 13.87 & 19.73 \\
\hline $31-50$ & 34 & 1312 & 3.77 & 11.63 \\
\hline $51-100$ & 30 & 2220 & 3.33 & 19.68 \\
\hline$>100$ & 22 & 4057 & 2.44 & 35.96 \\
\hline Total & 901 & 11283 & 100.00 & 100.00 \\
\hline
\end{tabular}


Table 3: Number of publications and citations and citation impact by top 10 most productive countries in limbic encephalitis, 2004-13

\begin{tabular}{|c|c|c|c|c|c|c|c|c|c|}
\hline \multirow[t]{2}{*}{ Country } & \multicolumn{3}{|c|}{ Number of publications } & \multicolumn{3}{|c|}{ Number of citations } & \multicolumn{3}{|c|}{ Average citation per publication } \\
\hline & 2004-08 & 2009-13 & $2004-13$ & 2004-08 & $2009-13$ & 2004-13 & 2004-08 & 2009-13 & 2004-13 \\
\hline USA & 65 & 128 & 193 & 815 & 1314 & 2129 & 12.54 & 10.27 & 11.03 \\
\hline Japan & 69 & 100 & 169 & 353 & 290 & 643 & 5.12 & 2.90 & 3.80 \\
\hline U.K. & 47 & 74 & 121 & 448 & 929 & 1377 & 9.53 & 12.55 & 11.38 \\
\hline Germany & 43 & 62 & 105 & 393 & 617 & 1010 & 9.14 & 9.95 & 9.62 \\
\hline France & 20 & 65 & 85 & 96 & 369 & 465 & 4.80 & 5.68 & 5.47 \\
\hline Spain & 22 & 34 & 56 & 265 & 863 & 1128 & 12.05 & 25.38 & 20.14 \\
\hline Italy & 15 & 27 & 42 & 105 & 273 & 378 & 7.00 & 10.11 & 9.00 \\
\hline Austria & 4 & 17 & 21 & 39 & 355 & 394 & 9.75 & 20.88 & 18.76 \\
\hline Australia & 6 & 15 & 21 & 34 & 195 & 229 & 5.67 & 13.00 & 10.90 \\
\hline Netherlands & 7 & 13 & 20 & 75 & 128 & 203 & 10.71 & 9.85 & 10.15 \\
\hline World & 311 & 590 & 901 & 2227 & 2964 & 5191 & & & \\
\hline
\end{tabular}

Table 4: Share of publication and citations and relative citation index by top 10 most productive countries in limbic encephalitis, 2004-13

\begin{tabular}{|c|c|c|c|c|c|c|c|c|c|}
\hline \multirow[t]{2}{*}{ Country } & \multicolumn{3}{|c|}{ Share of publications } & \multicolumn{3}{|c|}{ Share of citations } & \multicolumn{3}{|c|}{ Relative citation index } \\
\hline & 2004-08 & $2009-13$ & 2004-13 & 2004-08 & 2009-13 & $2004-13$ & 2004-08 & 2009-13 & 2004-13 \\
\hline USA & 20.90 & 21.69 & 21.42 & 36.60 & 44.33 & 41.01 & 1.75 & 2.04 & 1.91 \\
\hline Japan & 22.19 & 16.95 & 18.76 & 15.85 & 9.78 & 12.39 & 0.71 & 0.58 & 0.66 \\
\hline U.K. & 15.11 & 12.54 & 13.43 & 20.12 & 31.34 & 26.53 & 1.33 & 2.50 & 1.98 \\
\hline Germany & 13.83 & 10.51 & 11.65 & 17.65 & 20.82 & 19.46 & 1.28 & 1.98 & 1.67 \\
\hline France & 6.43 & 11.02 & 9.43 & 4.31 & 12.45 & 8.96 & 0.67 & 1.13 & 0.95 \\
\hline Spain & 7.07 & 5.76 & 6.22 & 11.90 & 29.12 & 21.73 & 1.68 & 5.05 & 3.49 \\
\hline Italy & 4.82 & 4.58 & 4.66 & 4.71 & 9.21 & 7.28 & 0.98 & 2.01 & 1.56 \\
\hline Austria & 1.29 & 2.88 & 2.33 & 1.75 & 11.98 & 7.59 & 1.36 & 4.16 & 3.26 \\
\hline Australia & 1.93 & 2.54 & 2.33 & 1.53 & 6.58 & 4.41 & 0.79 & 2.59 & 1.89 \\
\hline Netherlands & 2.25 & 2.20 & 2.22 & 3.37 & 4.32 & 3.91 & 1.50 & 1.96 & 1.76 \\
\hline World & 100.0 & 100.0 & 100.0 & 100.0 & 100.0 & 100.0 & & & 1.91 \\
\hline
\end{tabular}

in France, followed by Austria (1.59\%), USA (0.79\%) and Australia (0.61\%), as against decrease by $5.24 \%$ in Japan, Germany (3.32\%), U.K. (2.57\%), Spain (1.31\%), Italy $(0.24 \%)$, and Netherlands $(0.05 \%)$ from 2004 to 08-2009-13 [Table 2]. The global citation share of 10 most productive countries in limbic encephalitis varied from $4.48 \%$ to $41.01 \%$, with highest share $(41.01 \%)$ registered by USA, followed by U.K. (26.53\%), Spain (21.53\%), Germany (19.46\%), Japan (12.39\%), France (8.96\%), Austria (7.59\%), Italy (7.28\%), Australia (4.41\%) and e Netherlands (3.91\%) during 2004-13. The citation share has increased by $17.22 \%$ in Spain, followed by U.K. (11.22\%), Austria (10.23\%), France (8.14\%), USA (7.73\%), Australia (5.05\%), Italy $(4.50 \%)$, Germany $(3.17 \%)$ and Netherlands $(0.85 \%)$, as against decrease in Japan (6.07\%) from 2004 to 08-2009-13 [Table 3].

Of the top 10 most productive countries in limbic encephalitis, the highest (20.14) average citation per publication (ACPP) was achieved by Spain, followed by Austria (18.76), U.K.
(11.38), USA (11.03), Australia (10.90), Netherlands (10.15), Germany (9.62), Italy (9.0), France (5.47) and Japan (3.80) during 2004-13. The ACPP increased by 13.34 in Spain, followed by Austria (11.13), Australia (7.33), Italy (3.11), U.K. (3.02), France (0.88) and Germany (0.81), as against decrease by 2.22 in USA, followed by Japan (2.22) and Netherlands (0.87) from 2004 to 08-2009-13 [Table 2]. Only 3 out of 10 leading countries have achieved higher share of average relative citation index than the average of 1.91 of all top 10 countries during 2004-13: Spain (3.49), Austria (3.26) and U.K. (1.98). The relative citation rate has increased by 3.37 in Spain, followed by Austria (2.80), Australia (1.80), U.K. (1.17), Italy (1.03), Germany (0.70), Netherlands (0.47), France (0.46) and USA (0.29), as against decrease by 0.14 by Japan from 2004 to 08-2009-13 [Table 3].

\section{International Collaboration}

The highest international collaborative share (71.43) among the 10 most productive countries in limbic encephalitis 
during 2004-13 was registered by Austria, followed by Australia (57.14\%), Spain (51.79\%), U.K (42.19\%), Italy (40.48\%), Netherlands (40.00\%), Germany (38.10\%), USA (32.99\%), France (20.00\%) and Japan (8.88). Among the top 10 counties, the highest inter-country collaborative linkages were depicted by USA (64 linkages with 9 countries), followed by Spain (56 linkages with 8 countries), U.K. (56 linkages with 9 countries), Germany (49 linkages with 9 countries), Austria (42 linkages with 8 countries), Italy (42 linkages with 7 countries), etc., The strongest inter-country collaborative linkages (23 linkages) was between USA and Spain, followed by U.K. - Germany (20 linkages), USA-Japan (10 linkages), USA-Germany (10 linkages), U.K.-Italy (9 linkages), etc., [Table 5].

\section{Subject-wise Distribution of Publications}

The global publication output in limbic encephalitis has been considered in the context of five sub-fields (as indicated by Scopus database classification), with largest number of publications coming from medicine (with 91.56\% share), followed by neurosciences $(34.52 \%)$, biochemistry, genetics and molecular biology (6.77\%), psychiatry $(4.66 \%)$ and immunology and microbiology $(3.00 \%)$ during 2004-13. Using activity index concept for analyzing the trends in limbic encephalitis research, it was observed that the research activity had increased only in medicine sub-field (activity index increasing from 91.30 to 104.58), as against decrease in neurosciences (activity index decreasing from 120.17 to 94.28), biochemistry, genetics and molecular activity (activity index decreasing from 151.98 to 72.60 ), psychiatry (activity index decreasing from 137.96 to 79.99) and immunology and microbiology (activity

$\begin{aligned} & \text { Table 5: Share of collaborative publications and } \\
& \text { inter-country collaborative linkages among } \\
& \text { 10 leading } \\
& \text { countries in limbic encephalitis, } \\
& \text { 2004-13 }\end{aligned}$
\begin{tabular}{lcccccc} 
20untry & TP & ICP & $\begin{array}{c}\text { Percentage } \\
\text { of ICP }\end{array}$ & $\begin{array}{c}\text { Number of } \\
\text { collaborating } \\
\text { countries }\end{array}$ & $\begin{array}{c}\text { Number of } \\
\text { inter-country } \\
\text { collaborative } \\
\text { linkages }\end{array}$ \\
\hline USA & 194 & 64 & 32.99 & 9 & 64 \\
Japan & 169 & 15 & 8.88 & 7 & 19 \\
U.K. & 121 & 51 & 42.15 & 9 & 56 \\
Germany & 105 & 40 & 38.10 & 9 & 49 \\
France & 85 & 17 & 20.00 & 9 & 34 \\
Spain & 56 & 29 & 51.79 & 8 & 56 \\
Italy & 42 & 17 & 40.48 & 7 & 42 \\
Austria & 21 & 15 & 71.43 & 8 & 42 \\
Australia & 21 & 12 & 57.14 & 5 & 10 \\
Netherlands & 20 & 8 & 40.00 & 7 & 28 \\
\hline
\end{tabular}

$\mathrm{TP}=$ Total publications, ICP $=$ International collaborative publications index decreasing from 160.95 to 67.87 ) from 2004 to 08-2009-13. Neurology (among five sub-fields) had scored the highest citation impact per publication (7.78), followed by immunology and microbiology (6.48), biochemistry, genetics and molecular biology (3.59) and medicine (2.86) during 2004-13 [Table 6].

\section{Distribution of Publications by Type of Limbic Encephalitis Research}

Among the different types of limbic encephalitis research, comparatively much larger number of publications were observed in autoimmune limbic encephalitis (786 publications, $87.24 \%$ share) than in infectious limbic encephalitis (31 publications, 3.44\%) during 2004-13. The publication activity has decreased in both autoimmune limbic encephalitis (activity index decreasing from 100.99 to 99.48 ) and infectious limbic encephalitis (activity index decreasing from 102.80 to 98.52) from 2004 to 08-2009-13. Among the two sub-fields, autoimmune limbic encephalitis scored higher citation impact per publication of 5.58 compared to 3.10 in infectious limbic encephalitis during 2004-13 [Table 7].

\section{Distribution of Publications by Population Age Groups in Limbic Encephalitis}

On considering the global limbic encephalitis publications by different population age groups during 2004-13, it was observed that the largest share $(47.72 \%)$ of publications come from adults, followed by middle aged $(28.19 \%)$, aged $(19.20 \%)$, adolescents $(9.99 \%)$ and child $(6.99 \%)$. Of these population age groups, the publication share has decreased in adults (from $54.66 \%$ to $44.07 \%$ ), middle aged (from $36.66 \%$ to $23.73 \%$ ) and aged (from $21.86 \%$ to $17.80 \%$ ), as against increase in adolescent (from $8.04 \%$ to $11.02 \%$ ) and child (from $3.86 \%$ to $8.64 \%$ ) from 2004 to 08-2009-13 [Table 8].

\section{Scientometric Profile of Top 20 Most Productive World Organizations}

The global publications output in limbic encephalitis was published from 210 organizations, of which the top 10 have published 15-28 and together contributed 19.98\% (180 publications) share in the cumulative world publications output in limbic encephalitis during 2004-13. The scientometric profile of these 10 leading organizations is presented in Table 9. Only three organizations have registered higher publication productivity per organization 
Table 6: Subject-wise break-up of global publications in limbic encephalitis, 2004-13

\begin{tabular}{|c|c|c|c|c|c|c|c|}
\hline \multirow[t]{2}{*}{ Subject* } & \multicolumn{3}{|c|}{ Number of publications } & \multicolumn{2}{|c|}{ Activity index } & \multirow{2}{*}{$\begin{array}{l}\text { Number of } \\
\text { citations } \\
2004-13\end{array}$} & \multirow{2}{*}{$\begin{array}{c}\text { ACPP } \\
2004-13\end{array}$} \\
\hline & 2004-08 & 2009-13 & 2004-13 & 2004-08 & $2009-13$ & & \\
\hline Medicine & 260 & 565 & 825 & 91.30 & 104.58 & 2362 & 2.86 \\
\hline Neurosciences & 129 & 192 & 311 & 120.17 & 94.28 & 2421 & 7.78 \\
\hline Biochemistry, Genetics and Molecular Biology & 32 & 29 & 61 & 151.98 & 72.60 & 219 & 3.59 \\
\hline Psychiatry & 20 & 22 & 42 & 137.96 & 79.99 & 279 & 6.64 \\
\hline Immunology and Microbiology & 15 & 12 & 27 & 160.95 & 67.87 & 175 & 6.48 \\
\hline Total of world & 311 & 590 & 901 & 100.00 & 100.00 & & \\
\hline
\end{tabular}

*There is some overlapping of literature under different subjects. As a result, the combined global publications output under five subjects will be more than its total research output. $\mathrm{ACPP}=$ Average citations per publication

Table 7: Break-up of publication by type of limbic encephalitis, 2004-13

\begin{tabular}{|c|c|c|c|c|c|c|c|}
\hline \multirow[t]{2}{*}{ Subject } & \multicolumn{3}{|c|}{ Number of publications } & \multicolumn{2}{|c|}{ Activity index } & \multirow[t]{2}{*}{ Citations } & \multirow[t]{2}{*}{ ACPP } \\
\hline & 2004-08 & $2009-13$ & 2004-13 & $2004-08$ & $2009-13$ & & \\
\hline Autoimmune limbic encephalitis & 274 & 512 & 786 & 100.99 & 99.48 & 4389 & 5.58 \\
\hline Paraneoplastic & 261 & 466 & 727 & 104.01 & 97.89 & & \\
\hline Nonparaneoplastic & 23 & 32 & 55 & 121.15 & 88.85 & & \\
\hline Infectious limbic encephalitis & 11 & 20 & 31 & 102.80 & 98.52 & 96 & 3.10 \\
\hline Total of world & 311 & 590 & 901 & 100.00 & 100.00 & & \\
\hline
\end{tabular}

$\mathrm{ACPP}=$ Average citations per publication

Table 8: Break-up of limbic encephalitis publications by population age groups, 2004-13

\begin{tabular}{lccccccc}
\hline Subject & \multicolumn{3}{c}{ Number of publications } & \multicolumn{3}{c}{ Share of publications } \\
\cline { 2 - 4 } \cline { 6 - 8 } & $\mathbf{2 0 0 4 - 0 8}$ & $\mathbf{2 0 0 9 - 1 3}$ & $\mathbf{2 0 0 4 - 1 3}$ & & $\mathbf{2 0 0 4 - 0 8}$ & $\mathbf{2 0 0 9 - 1 3}$ & $\mathbf{2 0 0 4 - 1 3}$ \\
\hline Adults & 170 & 260 & 430 & 54.66 & 44.07 & 47.72 \\
Middle aged & 114 & 140 & 254 & 36.66 & 23.73 & 28.19 \\
Aged & 68 & 105 & 173 & 21.86 & 17.80 & 19.20 \\
Adolescent & 25 & 65 & 90 & 8.04 & 11.02 & 9.99 \\
Child & 12 & 51 & 63 & 3.86 & 8.64 & 6.99 \\
Total of world & 311 & 590 & 901 & 100.00 & 100.00 & 100.00 \\
\hline
\end{tabular}

than the group average (18.0): (i) University of Oxford, U.K. (28 publications), (ii) John Redcliffe Hospital, U.K. (22 publications) and (iii) Univerisitat Bonn, Germany (19 publications). Compared to this, six organizations have registered higher citation impact per paper than the group average (15.12) of 10 organizations during 2004-13: Universitat de Barcelona, Spain (23.28), University of Oxford, U.K. (18.86), Hospital Clinic Barcelona, Spain (18.75), John Redcliffe Hospital, U.K (18.45), Wheatherall Institute of Molecular Medicine, U.K. (17.00) and UCL, Institute of Neurology, U.K (16.69). Again only four organizations have achieved (i) higher h-index value than the group's average (9) during 2004-13: John Redcliffe Hospital, U.K (16), Universitat de Barcelona, Spain (12), University of Oxford, U.K (10) and Hospital Clinic Barcelona, Spain (10) during 2004-13 and (ii) higher ICP share than the group's average (48.89\%) during 2004-13: Wheatherall Institute of Molecular Medicine, U.K. (93.33), Universitat de Barcelona, Spain (77.78\%), John Redcliffe
Hospital (63.64\%) and University of Oxford, U.K. (50.00\%) and five organizations out of 10 have achieved relative citation index above the average relative index of 2.53 during 2004-13: Universitat de Barcelona, Spain (4.04), Hospital Clinic Barcelona, Spain (3.25), John Redcliffe Hospital, U.K (3.20), Wheatherall Institute of Molecular Medicine, U.K. (2.95) and UCL, Institute of Neurology, U.K (2.90).

\section{Research Communication in High Productive Journals}

The 15 most productive journals publishing global research output in limbic encephalitis during 2004-13 contributed 277 publications, which accounts for $30.74 \%$ share of the global output during 2004-13. The cumulative publications output share of these 15 most productive journals showed a decrease in global publications output from $37.30 \%$ during 2004-08-27.29\% during 2009-13. Considering the citation impact per paper made by these journals, the largest impact (143.45) was made during 2004-13 by the journal Brain, followed by Neurology (41.21), Journal of Neurology Neurosurgery and Psychiatry (23.50), Journal of Neurology (19.71, Epilepsia (14.00), etc) [Table 10].

\section{High Cited Publications}

There were 22 high cited publications, which received 4057 citations, leading to the average citation per publication of 184.41. These 22 high cited publications were published in 10 professional journals, namely Brain (5 publications), 
Table 9: Scientometric profile of 10 leading global organizations in limbic encephalitis during $2004-13$

\begin{tabular}{|c|c|c|c|c|c|c|c|}
\hline Name of organization & TP & TC & ACPP & $H$-index & ICP & Percentage of ICP & $\mathrm{RCl}$ \\
\hline University of Oxford, U.K. & 28 & 528 & 18.86 & 10 & 14 & 50.00 & 3.27 \\
\hline John Redcliffe Hospital, U.K. & 22 & 406 & 18.45 & 16 & 14 & 63.64 & 3.20 \\
\hline Univerisitat Bonn, Germany & 19 & 223 & 11.74 & 8 & 9 & 47.37 & 2.04 \\
\hline Universitat de Barcelona, Spain & 18 & 419 & 23.28 & 12 & 14 & 77.78 & 4.04 \\
\hline UCL, Institute of Neurology, U.K & 16 & 267 & 16.69 & 9 & 6 & 37.50 & 2.90 \\
\hline Universite Claude Bernard Lyon 1, France & 16 & 124 & 7.75 & 6 & 5 & 31.25 & 1.35 \\
\hline Hospital Clinic Barcelona, Spain & 16 & 300 & 18.75 & 10 & 7 & 43.75 & 3.25 \\
\hline Wheatherall Institute of Molecular Medicine, U.K. & 15 & 255 & 17.00 & 9 & 14 & 93.33 & 2.95 \\
\hline Mayo Clinic, USA & 15 & 122 & 8.13 & 6 & 2 & 13.33 & 1.41 \\
\hline Hospital Neurlogique et Neurochirsurgical Pierre Werthermer, France & 15 & 77 & 5.13 & 4 & 3 & 20.00 & 0.89 \\
\hline Total of 10 organizations & 180 & 2721 & 15.12 & 9 & 88 & 48.89 & 2.53 \\
\hline Total of the world & 901 & 5191 & & & & & \\
\hline Share of top 10 organizations in global output & 19.98 & & & & & & \\
\hline
\end{tabular}

$\mathrm{TP}=$ Total publications, $\mathrm{TC}=$ Total citations, $\mathrm{ACPP}=$ Average citation per publication, $\mathrm{ICP}=$ International collaborative publications, $\mathrm{RCI}=$ Relative citation index

Table 10: Leading media of communication in limbic encephalitis during 2004-13

\begin{tabular}{|c|c|c|c|c|c|}
\hline \multirow[t]{2}{*}{ Name of the journal } & \multicolumn{3}{|c|}{ Number of publications } & \multirow[t]{2}{*}{ Number of citations } & \multirow[t]{2}{*}{ ACPP } \\
\hline & 2004-08 & 2009-13 & 2004-13 & & \\
\hline Clinical Neurology & 26 & 24 & 50 & 88 & 1.76 \\
\hline Neurology & 14 & 15 & 29 & 1195 & 41.21 \\
\hline Brain and Nerve & 3 & 20 & 23 & 69 & 3.00 \\
\hline Journal of Neurology Neurosurgery and Psychiatry & 11 & 11 & 22 & 517 & 23.50 \\
\hline Journal of Neurology & 10 & 11 & 21 & 414 & 19.71 \\
\hline BMJ Case Reports & 0 & 21 & 21 & 2 & 0.10 \\
\hline Journal of Neurological Sciences & 7 & 8 & 15 & 122 & 8.13 \\
\hline Revue Neurologique & 6 & 8 & 14 & 63 & 4.50 \\
\hline Archives of Neurology & 2 & 12 & 14 & 194 & 13.86 \\
\hline Epilepsia & 2 & 11 & 13 & 182 & 14.00 \\
\hline Brain & 5 & 6 & 11 & 1578 & 143.45 \\
\hline Journal of Neuroimmunology & 5 & 6 & 11 & 197 & 17.91 \\
\hline European Neurology & 11 & 0 & 11 & 60 & 5.45 \\
\hline Internal Medicine & 3 & 8 & 11 & 118 & 10.73 \\
\hline Journal of Neuro-oncology & 11 & 0 & 11 & 127 & 11.55 \\
\hline Total of the 15 journals & 116 & 161 & 277 & 4926 & 17.78 \\
\hline Total global output & 311 & 590 & 901 & & \\
\hline Share of 15 journals in global output & 37.30 & 27.29 & 30.74 & & \\
\hline
\end{tabular}

$\mathrm{ACPP}=$ Average citations per publication

Lancet Neurology (4 publications), Neurology and Annals of Neurology (3 publications each), European Journal of Neurology (2 publications), Neurologists, Journal of Neurology, Journal of Neurology, Neurosurgery and Psychiatry, Lancet and Journal of Neuroscience (1 publications each). These 22 high cited publications involved 13 countries authors, including USA (14 publications), U.K. and Spain (4 publications each), Cyprus and Germany (2 publications each), Israel, Japan, Norway, France, South Korea, Canada, Netherlands and Italy (1 publications each). Of the 22 high cited publications, 12 involve national collaboration and 10 international collaboration.

\section{SUMMARY AND CONCLUSION}

The global output consisted of 901 publications in limbic encephalitis during 2004-13. It annually increased from 43 to 154 from the year 2004 to the year 2013, with an annual average publication growth rate of $17.27 \%$. The global publication output in limbic encephalitis registered a citation impact per paper of 5.76 during 2004-13, decreasing from 7.16 to 5.02 from 2004 to $08-2009-13$. Of the total global publications output in limbic encephalitis, $68.59 \%$ received one or more citations, of which $2.44 \%$ publications contributed $35.96 \%$ citations share, 3.33\% 
publications $19.68 \%$ citations share, $3.77 \%$ publications $11.63 \%$ citations share, $13.87 \%$ publications $19.73 \%$ citations share and the rest $45.17 \%$ publications $13.01 \%$ citations share.

The global limbic encephalitis research output originated in 48 countries, of which the top 10 countries produced $92.45 \%$ share of the total global output. United States alone contributed $21.42 \%$ publication share, followed by Japan (18.76\%), U.K. (13.43\%), Germany (11.65\%), France $(9.43 \%)$, Spain (6.22\%), Italy (4.66\%), Austria and Australia (2.33\% each) and Netherlands $(2.22 \%)$ during 2004-13. The publication share has increased in France, Austria, USA and Australia, as against decrease in Japan, Germany, U.K., Spain, Italy and Netherlands from 2004 to 08-2009-13. USA alone contributed $41.01 \%$ share in global citations output among 10 leading countries, followed by U.K. (26.53\%), Spain (21.53\%), Germany (19.46\%), Japan $(12.39 \%)$, France $(8.96 \%)$, Austria $(7.59 \%)$, Italy (7.28\%), Australia (4.41\%) and Netherlands (3.91\%) during 2004-13. The citation share had increased in Spain, U.K., Austria, France, USA, Australia, Italy, Germany and Netherlands, as against decrease in Japan from 2004 to $08-2009-13$. Only 3 out of 10 leading countries have achieved high share of relative citation index than the average value (1.91) of all 10 countries during 2004-13, namely: Spain (3.49), Austria (3.26) and U.K. (1.98).

The highest share (71.43\%) of international collaborative publications among ten leading countries was registered by Austria, followed by Australia (57.14\%), Spain (51.79\%), U.K (42.19\%), Italy (40.48\%), Netherlands (40.00\%), Germany (38.10\%), USA (32.99\%), France $(20.00 \%)$ and Japan (8.88). The highest inter-country collaborative linkages among 10 leading countries was depicted by USA, followed by Spain, U.K, Germany, Austria, Italy, etc., The highest number of inter-country collaborative linkages (23) among 10 leading countries was between USA and Spain, followed by U.K.-Germany (20 linkages), USA-Japan (10 linkages), USA-Germany (10 linkages), U.K.-Italy (9 linkages).

The global publications output in limbic encephalitis had been published in the context of five subject fields (as reflected by Scopus database classification), with highest number of publications coming from medicine $(91.56 \%$ share), followed by neurosciences (34.52\%), biochemistry, genetics and molecular biology (6.77\%), psychiatry (4.66\%) and immunology and microbiology (3.00\%) during 2004-13. On analyzing the trends using activity index, it was found that research activity has increased in medicine, as against decrease in neurosciences, biochemistry, genetics and molecular activity, psychiatry and immunology and microbiology from 2004 to 08-2009-13. Neurology had scored the highest citation impact per paper (7.78) among the five subjects, followed by immunology and microbiology (6.48), biochemistry, genetics and molecular biology (3.59) and medicine (2.86) during 2004-13.

Comparative much larger share of publications were reported in autoimmune limbic encephalitis (87.24\% share) than in infectious limbic encephalitis (3.44\%) during 2004-13. The publication activity has, however, decreased in both types of sub-fields from 2004 to 08-2009-13. Autoimmune limbic encephalitis also registered higher citation impact per publication (5.58) compared with infectious limbic encephalitis (3.10) during 2004-13.

The total research output on limbic encephalitis came from 210 organizations, of which the top 15 contributed $19.98 \%$ share to its total output during 2004-13. The average citation impact, relative citation index, h-index and share of ICPs registered by these 10 leading organizations were 15.12, 2.53, 9 and 48.89\%, respectively during 2004-13. Five organizations among 10 leading organizations have achieved relative citation index above the average relative index of 2.53 of all organizations: Universitat de Barcelona, Spain (4.04), Hospital Clinic Barcelona, Spain (3.25), John Redcliffe Hospital, U.K (3.20), Wheatherall Institute of Molecular Medicine, U.K. (2.95) and UCL, Institute of Neurology, U.K (2.90).

The 15 leading journals contributed $30.74 \%$ share of global publications output in limbic encephalitis during 2004-13, which decreased from $37.30 \%$ to $27.29 \%$ from 2004 to 08-2009-13. The highest citation impact per publication (143.45) was reported by the journal Brain among leading journals during 2004-13, followed by Neurology (41.21), Journal of Neurology Neurosurgery and Psychiatry (23.50), Journal of Neurology (19.71, Epilepsia (14.00), etc.

\section{REFERENCES}

1. Angela V, Camilla B. Limbic Encephalitis. Available from: http:// www.encephalitis.info/images/iPdf/Resources/FactSheets/ FS013Limbic Encephalitis.pdf. [Last accessed on 2014 June 29].

2. Sarosh RI, Angela V. Limbic encephalitis. The Encephalitis Society. Available from: http://www.encephalitis.info/information/ types-of-encephalitis/limbic-encephalitis/. [Last accessed on 2014 June 29].

3. Understanding the Basic Functions of the Limbic System. 
Available from: http://www.biology.answers.com/medicine/ understanding-the-basic-functions-of-the-limbic-system. [Last accessed on 2014 June 29].

4. The Encephalitis Society. The Encephalitis: The Illness. Available from: http://www.encephalitis.info/information/the-illness/. [Last accessed on 2014 June 29].

5. Garg KC, Sandhya D, Kumar S. Scientometric profile of vector borne diseases: A case study of global Japanese encephalitis research. SRELS J Inf Manage 2013;50:543-54.

6. Garg KC, Sandhya D. Pattern of collaboration on the discipline of Japanese Encephalitis. DESIDOC J Libr Inf Technol 2014;34:241-8.
7. Safahieh H, Sanni SA, Zainab1 AN. International contribution to Nipah Virus Research 1999-2010. Malays J Libr Inf Sci 2012;17:35-47.

8. Anne S. Scientometric analysis of the scientific relevance of the herpes simplex virus. Department of Medicine-Charité-University Medicine Berlin. German: Doctoral Thesis; 2010.

How to cite this article: Gupta R, Gupta BM, Mueen M. Limbic encephalitis: A scientometric analysis of global publications during 2004-13. J Sci Res 2014;3:125-33.

Source of Support: Nil, Conflict of Interest: None declared

\section{Author Help: Online submission of the manuscripts}

Articles can be submitted online from http://www.journalonweb.com. For online submission, the articles should be prepared in two files (first page file and article file). Images should be submitted separately.

1) First Page File:

Prepare the title page, covering letter, acknowledgement etc. using a word processor program. All information related to your identity should be included here. Use text/rtf/doc/pdf files. Do not zip the files.

2) Article File:

The main text of the article, beginning with the Abstract to References (including tables) should be in this file. Do not include any information (such as acknowledgement, your names in page headers etc.) in this file. Use text/rtf/doc/pdf files. Do not zip the files. Limit the file size to $1 \mathrm{MB}$. Do not incorporate images in the file. If file size is large, graphs can be submitted separately as images, without their being incorporated in the article file. This will reduce the size of the file.

3) Images:

Submit good quality color images. Each image should be less than $4096 \mathrm{~kb}(4 \mathrm{MB})$ in size. The size of the image can be reduced by decreasing the actual height and width of the images (keep up to about 6 inches and up to about $1800 \times 1200$ pixels). JPEG is the most suitable file format. The image quality should be good enough to judge the scientific value of the image. For the purpose of printing, always retain a good quality, high resolution image. This high resolution image should be sent to the editorial office at the time of sending a revised article.

4) Legends:

Legends for the figures/images should be included at the end of the article file. 